\title{
CAUSAS E IMPACTOS DAS QUEIMADAS NO MARANHÃO
}

\author{
Alexandre Oliveira Alves ${ }^{\mathrm{a}}$; Cristielen de Oliveira Pozza ${ }^{\mathrm{a}}$; Cristiana Araujo Soares ${ }^{\mathrm{a}}$; João Victor Jansen \\ de Queiroz ${ }^{\mathrm{a}^{*}}$ \\ a Intituto Estadual de Educação, Ciência e Tecnologia do Maranhão, São José de Ribamar, MA. Brasil. \\ *E-mail para correspondência:jiansenq@outlook.com
}

\section{Palavras-chave: \\ Focos de incêndios; Meio ambiente; Prejuízos.}

\section{Keywords:}

Environment; Fire outbreaks; Losses.

\section{RESUMO}

Os números de registros de focos de incêndio aumentam a cada ano, o que se torna preocupante, pois o fogo provoca prejuízos à saúde humana e ao meio ambiente. Este trabalho teve por objetivo identificar as principais causas e os principais impactos das queimadas no estado do Maranhão. Para realização desta pesquisa efetuou-se uma revisão bibliográfica baseada em artigos e leis que abordam essa temática, coletou-se também dados referentes às quantidades de focos de queimadas disponibilizados no site do Instituto Nacional de Pesquisas Espaciais (Inpe) e junto ao Corpo de Bombeiro Militar do Maranhão (CBMMA). As causas das queimadas estão diretamente relacionad as a fatores climáticos ou pelo exercício de atividades antrópicas, que fazem do solo seu principal meio de produção. Dentre os principais impactos dessa prática estão os danos provocados à saúde humana, as alterações nas propriedades físicas, químicas e biológicas do solo e a diminuição da biodiversidade da área.

\section{ABSTRACT}

The number of records of fire outbreaks increases each year, which is cause for concern, because fire causes damage to human health and the environment. This work aimed to identify the main causes and impacts of fires in the state of Maranhão. In this research, was carried out a bibliographic review based on articles and laws about the theme, data were collected about the number of fire outbreaks, available on website of National Institute for Space Research (Inpe) and with Military Fire Brigade of Maranhão (CBMMA). The causes of fires are directly related to climatic factors or to exercise of anthropic activities, which make the soil their main means of production. Among the main impacts of this practice are damage caused to human health, changes in the physical, chemical and biological properties of soil and decrease of biodiversity.

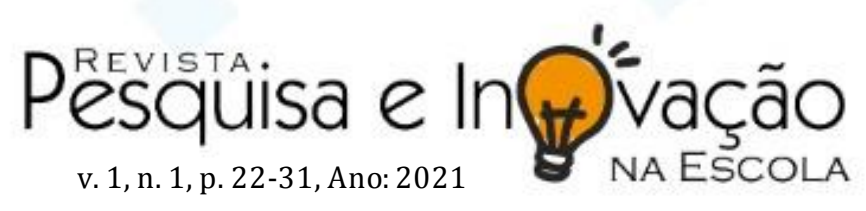




\section{INTRODUÇÃO}

Em um país como o Brasil, com grandes proporções continentais e ritmo de desenvolvimento constante, a agricultura mostra-se como uma das principais atividades econômicas. Em contrapartida, com o avanço do agronegócio surgem alguns problemas, que em sua maioria despertam grandes preocupações em entidades ambientalistas e na comunidade internacional, como por exemplo, aumento do número de queimadas. As queimadas tornam-se cada vez mais uma técnica obsoleta e criminosa, haja vista que são utilizadas em grande parte na limpeza do terreno para o cultivo ou formação de pastos. A execução dessa técnica, sem o aval de um órgão ambiental é classificada como incêndio com viés criminoso e é acometida por pena assegurada na Lei Nacional de Crimes Ambientais, Lei no 9.605/98 (BRASIL, 1998).

Uma das primeiras medidas no âmbito ambiental, foi a Lei do Código Florestal (Lei ${ }^{\circ}$ 4.771/65), que em seu artigo 27 estabeleceu que é proibido o uso do fogo em quaisquer áreas remanescentes de reflorestas e demais vegetações (BRASIL, 1965). Entretanto, o parágrafo único deste mesmo artigo apresenta exceções em alguns casos, tais como para fins agropastoris ou florestais onde as características da região justificarem o uso dessa prática, sendo que a permissão deverá ser analisada pelo poder público ou órgão ambiental regularizado, a fim de evitar danos ao meio ambiente (GARCIA, 2011). Em 1989, após 24 anos da validação da Lei do Código Florestal, entra em vigor o decreto ${ }^{\circ}$ 97.635/89, que ratifica e condena o uso do fogo sem controle nas lavouras. Nove anos após, foi sancionada a Lei Nacional de Crimes Ambientais (Lei $n^{\circ}$ 9.605/98), determinando sanções administrativas e legais às atividades danosas ao meio ambiente.

O Instituto Nacional de Pesquisas Espaciais (Inpe), em junho de 2020, registrou 2.248 queimadas nos biomas que ficam em território brasileiro, dentre eles os mais afetados são o Cerrado e o Bioma Amazônico. Desde 2007 o mês de junho não ultrapassava a marca de 2.000 incidências de fogo, comparando com os valores do ano de 2020, os dados revelam um aumento significativo de 19,6\%, pois em junho de 2019 a instituição registrou 1.880 focos (INPE, 2020).

No Maranhão os focos cresceram 73,5\% no mês de julho de 2020, em comparação com o mesmo período de 2019, revelando que enquanto em julho de 2019 ocorreram 86 focos de incêndio, em 2020 esse número subiu para 242, deixando o Maranhão em primeiro lugar no ranking de queimadas entre os estados do Nordeste (INPE, 2020).

O Cerrado Maranhense ocupa 64\% do território do Estado, seguido pelo Bioma Amazônico que compreende $35 \%$ e a Caatinga que ocupa cerca de $1 \%$ da área total do estado (ARAUJO et al., 2016). No período de estiagem, um dos biomas mais atingidos pela baixa

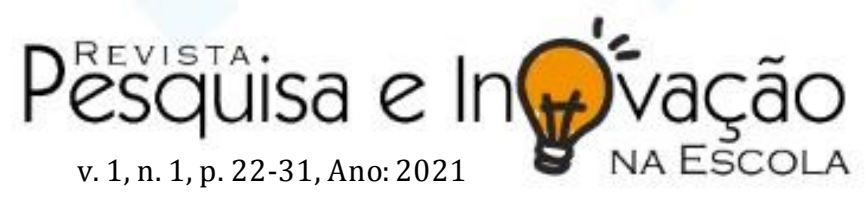


umidade relativa do ar e fatores naturais, é o Cerrado, que concentra-se em sua maioria nas regiões Sul e Centro-Oeste do estado do Maranhão, nos quais se encontram cidades com grande potencial agrícola, como Grajaú, Mirador, Balsas e Alto do Parnaíba, observando-se também que as mesmas foram classificadas como as quatros cidades do Maranhão com maior incidência de focos de incêndio nos anos de 2014 e 2015 (SALES et al., 2019).

Diante do crescente número de queimadas observadas no decorrer dos anos, mesmo sendo uma prática com restrições conforme consta na legislação, este trabalho teve por objetivo identificar as principais causas e os impactos das queimad as no estado do Maranhão.

\section{METODOLOGIA}

Este trabalho foi elaborado a partir de uma revisão bibliográfica pesquisando artigos (2002 a 2019), nas ferramentas disponíveis na web, como Google Acadêmico (https://scholar.google.com.br/?hl=pt), e Scientific Eletronic Library Online - Scielo (https://scielo.org/), a busca foi realizada com a combinação de palavras-chave como "Queimadas no Maranhão", "Causas das Queimadas", "Impactos das Queimadas" e "Danos provocados pelas queimadas". Também se pesquisou dados em leis que abordam o assunto como a Lei do Código Florestal (Lei ${ }^{\circ}$ 4771/65) e a Lei Nacional de Crimes Ambientais (Lei $\mathrm{n}^{\circ}$ 9.605/98). E para coleta de dados referentes à quantidade de focos de queimad as consultouse os sites do Instituto Nacional de Pesquisas Espaciais (Inpe) e do Corpo de Bombeiro Militar do Maranhão (CBMMA).

\section{RESULTADOS E DISCUSSÃO}

O Maranhão é um dos estados da região Nordeste com um dos maiores potenciais agroeconômicos, ocupando o segundo lugar em produtividade no cultivo de soja. Segundo dados da consultoria mundial em análise do mercado agrícola (ARC Mercosul), na região do cerrado o estado apresentou crescimento de 5,8\% na área plantada e 1,1\% de hectares na safra de 2019/2020 (SEINC-MA, 2020). Dados da terceira fase do Plano de ação para prevenção e controle do desmatamento no Cerrado, criado pelo Ministério do Meio Ambiente (MMA), apontam que o aumento de queimadas no Cerrado está diretamente ligado ao aumento das atividades agrícolas no bioma (BRASIL, 2018).

No Maranhão, as queimadas se concentram na região de domínio do cerrado, região que abriga o polo agrícola da soja no estado. As atividades agroeconômicas são em sua maioria responsáveis pelo incremento do grande quantitativo de focos de incêndios, dentre elas, a

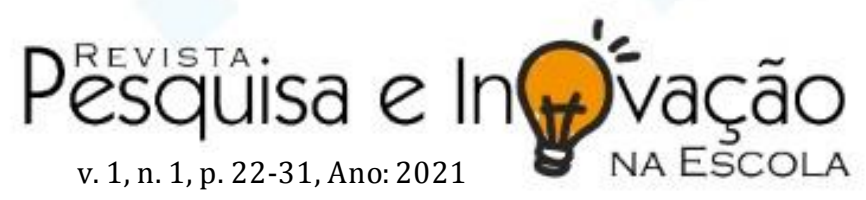


pecuária, a agricultura de larga escala e a agricultura de corte e queima, que fazem do solo seu principal meio de produção (SALES et al., 2019).

Segundo Carlos Nobre, pesquisador do Instituto de Estudos Avançados da Universidade de São Paulo (USP), e presidente do Painel Brasileiro de Mudanças Climáticas (PBMC), o pequeno agricultor utiliza o fogo, mas relativamente os números de áreas queimadas por eles é substancialmente menor, sendo em sua maioria o grande contingente de focos de queimadas se dá pela expansão de grandes propriedades (BBC BRASIL, 2020).

O súbito aumento no número de focos de queimadas está associado a diversos fatores dentre eles, climáticos ou por atividades antrópicas, que aceleram o processo de alteração da paisagem natural de áreas florestais. O agronegócio, as mineradoras e as madeireiras contribuem para o alto índice de desmatamento e queimadas registrados no estado do Maranhão (SALES et al., 2019).

De acordo com dados do Corpo de Bombeiros Militar do Maranhão (CBMMA), o período com maior incidência de focos de queimad as no estado está entre os meses de agosto a setembro, época mais crítica da estiagem no Maranhão (ASCOM-BM, 2019). Segundo dados do Inpe, os altos índices de queimadas registradas nesses meses, levam o Maranhão ao $3^{\circ}$ lugar no ranking de queimadas em 2020 no país (INPE, 2020).

Outro frequentemente motivo para o alto índice de focos de queimadas no Maranhão está relacionado a casos simples, como de pequenos produtores rurais, que originam os focos de incêndio através do preparo da terra para a chamada "roça de toco" (Figura 1), técnica muito utilizada por agricultores de baixo poder aquisitivo, método considerado arcaico, que consiste em atear fogo para limpeza e preparo do solo para o plantio. A utilização do fogo como instrumento de limpeza pode desencadear uma atividade perigosa e nociva ao meio ambiente, fugind o de controle e provocando uma grande queimada (SILVA JUNIOR et al., 2016).

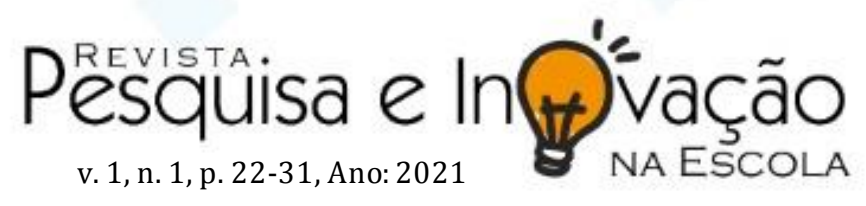


Figura 1: Área queimada para instalação de "roça de toco".

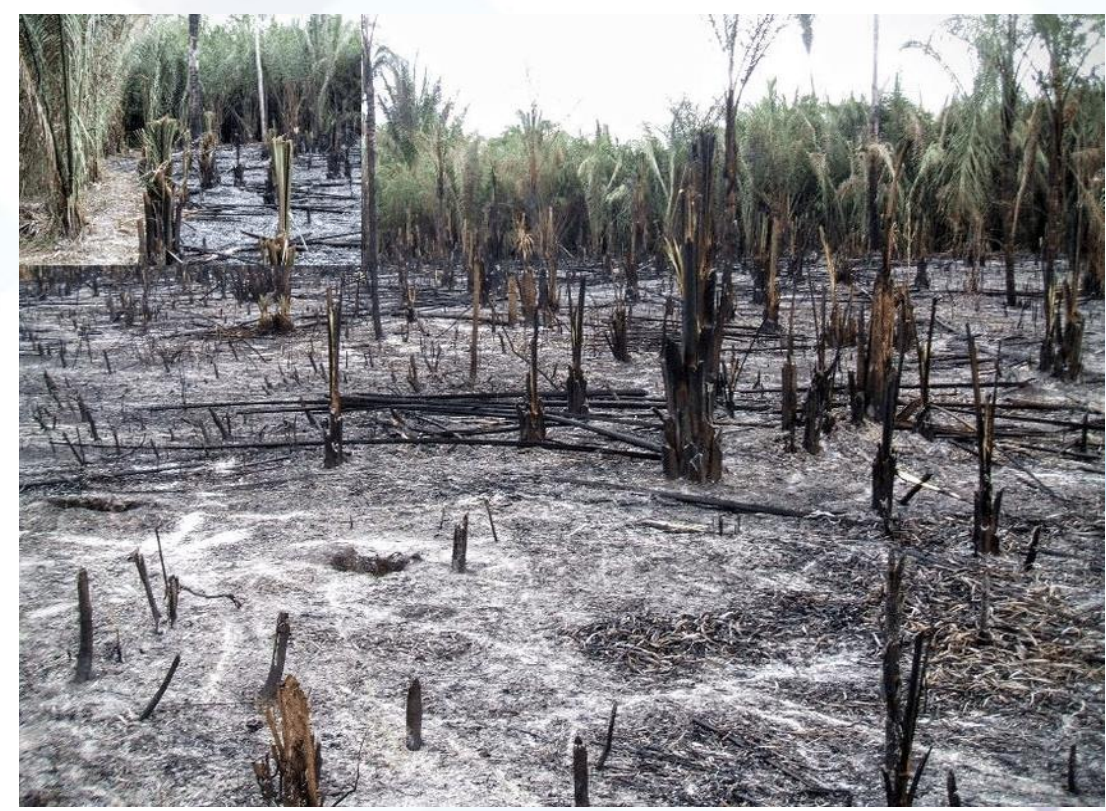

Fonte: Moraes (2013), apud Silva Junior et al. (2016)

Dados do Inpe, revelam que no mês de julho de 2020, as queimadas cresceram em comparativo ao mesmo período de 2019, em geral 982 novos focos de queimadas surgiram nos Biomas brasileiros. Dentre os estados brasileiros, o Maranhão registrou no ano de 202016.817 queimadas, ficand o atrás apenas dos estad os do Mato Grosso e Pará, que contabilizaram 47.708 e 38.603 de queimadas, respectivamente (INPE, 2020).

Observa-se na Tabela 1, que os quatro municípios da região de domínio do cerrado maranhense que apresentaram maiores focos de queimadas no ano de 2020 foram Mirador, Alto Parnaíba, Balsas e Fernand o Falcão, registrand o 1.136, 961, 737 e 602 focos, respectivamente. Sales et al. (2019) investigando os municípios do Maranhão mais atingidos com focos de queimadas nos anos de 2014 e 2015 também apontou Mirador, Balsas e Alto do Parnaíba com grande registros de focos de queimadas, com valor médio de 1.380 focos em Mirador, 1.118 focos em Balsas e 1.056 focos em Alto do Parnaíba. 
Tabela 1: Municípios maranhenses com maiores focos de queimadas em 2020.

\begin{tabular}{lc}
\hline Municípios maranhenses & $\mathbf{N}^{\circ}$ de focos de incêndio \\
\hline Mirador & 1.136 \\
Alto Parnaíba & 961 \\
Balsas & 737 \\
Fernando Falcão & 602 \\
Riachão & 442 \\
Grajaú & 422 \\
Carolina & 386 \\
Parnarama & 341 \\
Amarante do Maranhão & 287 \\
Barra do Corda & 266 \\
\hline Total & $\mathbf{5 . 5 8 0}$ \\
\hline
\end{tabular}

Os altos índices de queimadas estão associados ao clima tropical sazonal, de inverno seco característico na região de domínio do cerrado e pelo grande aumento das atividades agroind ustriais que utilizam o solo dessa região como seu principal meio de produção (INPE, 2020).

Um dos fatores que também contribuem para o incremento do número de queimadas está associado a coleta de resíduos sólidos das cidades, haja vista que em muitos municípios os bairros periféricos e com menor infraestrutura geralmente não são atendidos com coletas de lixo regulares, então muitos moradores encontram no fogo uma alternativa para se livrar desses resíduos. Também é importante mencionar que mesmo em áreas atendidas regulamente com a coleta de lixo, ainda se pode detectar focos de incêndios, pois alguns materiais não são recolhidos, como por exemplos os resíduos de poda de árvores, sendo estes eliminados na maioria das vezes através da queima no próprio quintal e/ou depositados em terrenos baldios com posterior queima. Ribeiro e Assunção (2002) também relatam que o fogo é utilizado para queima do lixo e outros materiais das residências, e alertam que após entrarem em combustão são tóxicos a saúde das pessoas e ao meio ambiente.

O fogo ocasiona várias modificações no solo, podendo interferir em suas características físicas, químicas e biológicas. Essas alterações podem ocorrer de forma direta e indireta e

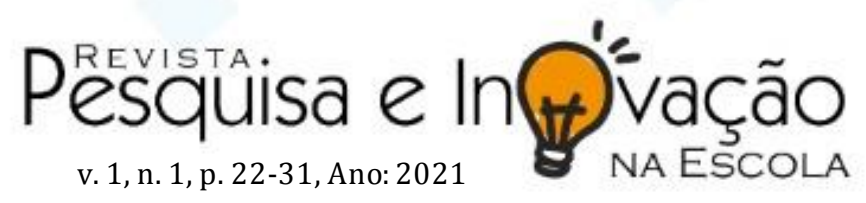


também podem ter efeitos pontuais e/ou permanentes, dependendo do tipo de solo, da cobertura vegetal, da duração e intensidade da queima e da frequência de utilização (REDIN et al., 2011).

Nas características físicas do solo, o fogo ocasiona diminuição da porcentagem de macroporos, aumento da densidade do solo, aumento da resistência à penetração das raízes das plantas, redução no tamanho dos agregados, diminuição da quantidade de água infiltrada no perfil do solo e ainda expõe a superfície do solo, através da retirada da vegetação, aumentando a possibilidade de ocorrer erosão (REDIN et al., 2011).

De acordo com os mesmos autores, quando se considera as características químicas do solo, percebe-se um aumento nas quantidades de Nitrogênio (N), Fósforo (P), Potássio (K), Cálcio (Ca) e Magnésio ( $\mathrm{Mg}$ ) e outros, que são mineralizados após a passagem do fogo. O aumento nos teores de alguns nutrientes é devido o processo de mineralização que ocorre com a queima, ficando os mesmos retidos nas cinzas, e como as plantas absorvem nutrientes mineralizados é normal que elas cresçam rapidamente, porém esse efeito é temporário (RHEINHEIMER etal., 2003). De acordo com Knicker (2007) apud Redin et al. (2011) o efeito da elevação de nutrientes no solo desaparece em médio prazo, devido à lixiviação dos mesmos pela chuva, resultando em teores inferiores aos observados no solo antes da queimada. Essa afirmação é facilmente constatada, basta observar que os pequenos produtores mudam constantemente seus locais de plantio em decorrência da diminuição de produtividade, buscando áreas mais férteis, onde será efetuada a próxima queima.

Em relação às características biológicas do solo, o fogo apresenta efeito negativo, reduzindo a quantidade de microrganismo presente no solo, tanto pela elevada temperatura como pela diminuição dos teores de matéria orgânica, que são alimentos desses organismos (REDIN et al., 2011). Wikars e Schimmel (2001) apud Redin et al. (2011) estudando a influência da intensidade do fogo e do grau de desmatamento sobre a fauna do solo observaram uma redução do número de espécies presentes logo após a queima.

As queimadas também ocasionam sérios problemas na saúde humana, send o maiores os efeitos quanto mais próximos às pessoas estiverem dos focos de queimadas. Contudo o direcionamento e a intensidade dos ventos exercem direta influência na dispersão dos fragmentos oriundos da queima, os quais se proliferam pela atmosfera atingindo grande área populacional. Ribeiro e Assunção (2002) relatam que através das queimadas são emitidos diversos poluentes, entre eles o Monóxido de carbono (CO) e o Hexacloreto (HC), que são substâncias altamente tóxicas a saúde humana, tendo efeitos que vão de intoxicação até morte por asfixia ou pela redução da oxigenação em níveis críticos e pela alta concentração de

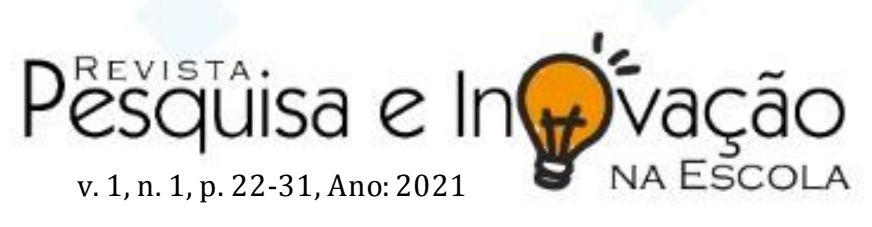


monóxido de carbono nas vias respiratórias. Os efeitos da queima também podem ocasionar irritação nos olhos e garganta, tosse, falta de ar, nariz entupido, vermelhidão e alergia na pele e até desordens cardiovasculares (RIBEIRO; ASSUNÇÃO, 2002).

Além dos danos causados à saúde humana, as queimadas afetam diretamente o meio ambiente, a ação do fogo impacta negativamente na biodiversidade da área, afetando tanto a flora quanto a fauna. Dependendo da intensidade do fogo pode haver destruição parcial ou total da cobertura vegetal, morte de vários animais silvestre, migração dos sobreviventes para outras áreas em busca de abrigo e alimento. Medeiros e Fiedler (2004) afirmam que a ocorrência de incêndios florestais é uma ameaça a conservação da biodiversidade e manutenção de processos ecológicos.

\section{CONSIDERAÇÕES FINAIS}

Os altos índices de ocorrências de queimadas em todo território do Maranhão, estão diretamente relacionados a pequenos e grandes produtores rurais, que originam os focos de incêndio através do preparo da terra e também por fatores associadas à coleta de resíduos sólidos, onde moradores encontram no fogo uma alternativa para se livrar desses resíduos. Os municípios maranhenses que obtiveram maiores incidências de focos de queimadas em 2020 foram Mirador, Alto Parnaíba, Balsas e Fernando Falcão, totalizando 3.436 focos .

As queimadas causam danos à saúde humana, provocam alterações nas propriedades (físicas, químicas e biológicas) dos solos e reduzem à biodiversidade. O impacto do fogo modifica a densidade do solo, reduz a capacidade de retenção de água, modifica a fertilidade natural e elimina microrganismos importantes. Na saúde pública, a emissão de gases tóxicos liberados durante a queima provoca intoxicações, asfixias, crises de asma, rinite, bronquite e diminuição da oxigenação no corpo. $\mathrm{O}$ fogo reduz a biodiversidade da flora e fauna da área, fazendo com que os animais sobreviventes migrem para outras áreas em busca de abrigo e alimento.

\section{AGRADECIMENTOS}

Ao Instituto de Educação, Ciência e Tecnologia do Maranhão (IEMA), pelo ensino de qualidade e pelo título de Técnico em Agricultura.

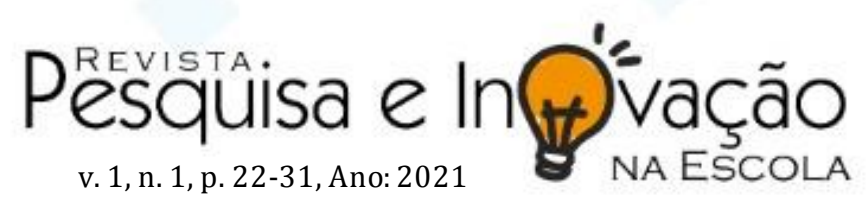




\section{REFERÊNCIAS}

ARAÚJO, L. S. et al. Conservação da biodiversidade do estado do Maranhão: cenário atual em dados geoespaciais, Jaguariúna: Embrapa Meio Ambiente, 2016. 28 p. Disponível em: https://ainfo.cnptia.embrapa.br/digital/bitstream/item/159940/1/Serie-Documentos-108Luciana.pdf. Acesso em: 19 set. 2020.

ASCOM-BM: Assessoria de Comunicação dos Bombeiros Militares do Maranhão. Informativo Maranhão sem queimadas. São Luís, 2019. Disponível em: https://cbm.ssp.ma.gov.br/index.php/2019/10/01/informativo-cbmma-maranhao-semqueimadas-2. Acesso em: 05 out. 2020.

BBC BRASIL: British Broadcasting Corporation. Amazônia: agricultores causam maioria das queimadas, e não índios e caboclos. Brasília, 2020. Disponível em: https://www.bbc.com/portuguese/brasil-54259838. Acesso em: 05 out. 2020.

BRASIL. Lei Federal $\mathbf{n}^{0}$ 9.605, de 12 de fevereiro de 1998. Dispõe sobre as sanções penais e administrativas derivadas de condutas e atividades lesivas ao meio ambiente, e dá outras providências. Disponível em: http://www.planalto.gov.br/ccivil_03/leis/19605.htm. Acesso em: 20 set. 2020.

BRASIL. Lei Federal no 4.771, de 15 de setembro de 1965. Institui o novo Código Florestal. Disponível em: https://www2.camara.leg.br/legin/fed/lei/1960-1969/lei-4771-15-setemb ro1965-369026-publicacaooriginal-1-pl.html. Acesso em: 06 set. 2021.

BRASIL. Ministério do Meio Ambiente. Plano de ação para prevenção e controle do desmatamento no cerrado (PPC 2026-2020). Brasília, 2018. Disponível em: https://www.mma.gov.br/informma/item/618-ppcerrado.html. Acesso em: 30 set. 2020.

GARCIA, A. R. Queimadas. Nippo no Campo, São Paulo. 2011. Disponível em: https://www.nippo.com.br/campo/lei/lei432.php\#: :text=A\%20queimada\%20sem\%20licen\% C3\%A7a\%20do,\%C3\%B3rg\%C3\%A3o\%20ambiental\%20de\%20sua\%20cidade. Acesso em: 15 set. 2020.

INTITUTO NACIONAL DE PESQUISAS ESPACIAIS (INPE). Programa queimadas: queimadas e incêndios florestais. São José dos Campos, 2020. Disponível em: https://queimadas.dgi.inpe.br//queimadas/bdqueimadas\#graficos. Acesso em: 06 nov. 2020 e 10 abr. 2021.

MEDEIROS, B. M.; FIEDLER, C. N. Incêndios florestais no parque nacional da Serra da Canastra: Desafios, Ciência Florestal, Santa Maria, v.14, n. 2, p. 157-168, 2004. Disponível em: https://www.scielo.br/pdf/cflo/v14n2/1980-5098-cflo-14-02-00157.pdf. Acesso: 23 out. 2020.

REDIN, M. et al. Impactos da queima sobre atributos químicos, físicos e biológicos do solo, Ciência Florestal, Santa Maria, v. 21, n. 2, p. 381-392, 2011. Disponível em: https://periodicos.ufsm.br/cienciaflorestal/article/view/3243. Acesso em: 08 de out. 2020.

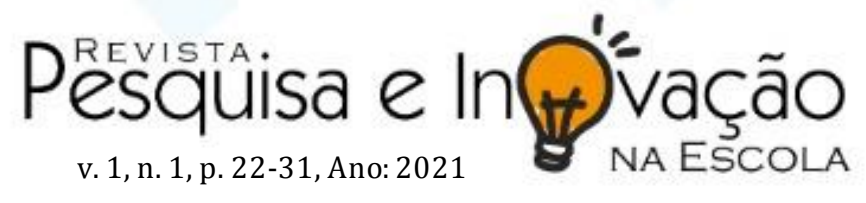


RHEINHEIRMER, D. S. et al. Modificações nos atributos químicos do solo sob campo nativo submetido à queima, Revista Rural, Santa Maria, v. 33, n. 1, p. 49-55, 2003. Disponível em: https://www.scielo.br/pdf/cr/v33n1/14142. Acesso em: 8 de out. 2020.

RIBEIRO, H.; ASSUNÇÃO, J. V. Efeito das queimadas na saúde humana. Estudos Avançados, São Paulo, v. 16, n. 44, p. 125-148, 2002. Disponível em: https://www.scielo.br/scielo.php?script=sci_arttext\&pid=S0103-40142002000100008. Acesso em: 09 out. 2020.

SALES, L. L. N. et al. 10 Municípios maranhenses mais atingidos por focos de queimadas nos anos de 2014 e 2015, Revista de Geografia, Recife, v. 36, n. 1, p. 59-74, 2019. Disponível em: https://periodicos.ufpe.br/revistas/revistageografia/article/view/230387. Acesso em: 04 set. 2020.

SILVA JUNIOR, C. H. L. et al. Dinâmicas das queimadas na baixada maranhense, Revista de Geografia, Grajaú, v. 2, n. 5, p. 355-375, 2016. Disponível em: http://www.periodicoseletronicos.ufma.br/index.php/interespaco/article/view/5287. Acesso em: 09 out. 2020.

SEINC-MA. Maranhão plantou mais de 1 milhão de hectares de soja na safra 2019/2020, 2020. Disponível em: http://www.seinc.ma.gov.br/2020/01/maranhao-plantou-mais-de-1milhao-de-hectares-de-soja-na-safra-2019-20/. Acesso em: 28 set. 2020. 